\title{
Arbor
}

\section{Toledo desde dentro}

José Botella Llusiá

Arbor CLXX, 671-672 (Noviembre-Diciembre 2001), 461-472 pp.

\section{Toledo y yo}

Yo, no soy de Toledo. Nací en un barrio de Madrid, que por entonces era aún "galdosiano». Y aunque esto puede darme un aire de Angel Guerra, la verdad es que no es a través de Don Benito, como le ocurrió a Marañón; del modo que yo he conocido la «Imperial Ciudad». Y ya de entrada digo, que no voy a emplear mas esto de «imperial», por que no me gusta nada y os diré por qué.- No pido que se quite el águila austríaca de su escudo, pero Toledo era grande; es más tenía su verdadera fisonomía ya perfectamente dibujada, antes que viviese en ella el Emperador Carlos y antes también de que aquí, en el Palacio de Fuensalida, muriese su bella Ysabel. Siempre en guerras y fuera de España, vivió muy poco junto al Tajo La ciudad era imperial en sus ideas, en sus sueños y hasta si se quiere, lo fue en la Edad Media; en la época de las tres religiones. Pero no cuando los escudos lo proclaman, si no antes y de un modo más difuso, mas ideal.

Ya digo, que ni a través de Galdós, ni tampoco de Don Gregorio - con ser fiel discípulo suyo- he entrado yo en esta ciudad. La he conocido en mi infancia y con ella he soñado mucho antes de tener mi «Jardín del Moro». Ahora os contaré de que manera. Pero dejarme antes que os diga, que a pesar de vivir aquí una tercera parte de la semana, y a despecho de que siendo rector complutense, traje por primera vez y por decisión mía personal — que buenos disgustos me costó- los estudios universitarios; no tengo el honor de ser toledano. He conocido a media docena de alcaldes y todos o casi todos me han prometido hacerme «hijo adoptivo» pero después, nada de nada. No me importa, por que yo he hecho a la ciudad, a su casco viejo amurallado; 
mi «Madre adoptiva» y esa honra autoproclamada, ya nadie me la puede quitar.

\section{Un viejo maestro}

$\mathrm{Y}$ ahora quisiera contaros, de que modo vine yo por primera vez aquí: No tenía mas de once o doce años y era alumno del Instituto Escuela - que es una lástima que haya desaparecido, por que fue una experiencia educativa genial que hubiera hecho y que sigue haciendo, mucha falta en España-Y entre las cosas originales que tenía aquel colegio, era que todos los Domingos del curso, nos traían a ver alguna vieja ciudad de Castilla. Lo mas lejos que se podía ir entonces en un día desde Madrid, era a Toledo, al Escorial, a Alcalá, a Guadalajara, a Avila o a Segovia. Ya para Salamanca no alcanzaba el tiempo. Aquí veníamos mas de un domingo cada curso. Nos traía siempre Don Francisco Barnés, que entonces, aunque a mi me parecía muy viejo por su gran barba, apenas debía tener cuarenta o cuarenta y cinco años. Barnés era un institucionista discípulo de Giner y sobre todo de Cossío. Era catedrático de Historia en el Instituto de Avila, de donde lo pescó Castillejo para fundar el Instituto Escuela. Era un pedagogo integral que sacrificaba su vida entera a la enseñanza de los arrapiezos que éramos nosotros entonces. Es lástima, que este hombre que llegó en 1932 a ser ministro de Instrucción Pública de la República, no tenga un monumento en Avila, en Toledo o en Madrid. Lo tiene desde luego, en mi corazón

Nos trajo a Toledo muchos domingos, pero recuerdo uno especialmente: Era un día ya casi en verano, a fin de curso, por San Juan. Veníamos en el tren y nos bajamos en esa estación neomudéjar tan bella, que por entonces se estrenaba. En días anteriores, ya habíamos visto la Catedral, el Alcázar, y por cierto San Juan de la Penitencia que todavía estaba intacta Esta vez que digo, no entramos en Toledo; tomamos a pié el camino viejo de la Sisla — que también estaba todavía viva- y después de visitarla nos fuimos andando a campo traviesa hasta la Peña del Moro y allí, a la vista de Toledo, sacamos de los morralitos las meriendas - Barnés con nosotros- y nos pusimos a comer. Y tras el breve almuerzo, viendo aquel paisaje, que entonces sin hacer la carretera de circunvalación y mucho menos el Parador de Turismo, era rigurosamente inédito; el maestro nos explicaba la decadencia de Toledo a fines del XVI. Nos hablaba de la ruina, lejana aún, pero que se veía ya venir. Nos contaba, de aquellos viejos caballeros, que en sus corrillos después de la misa de la mañana, recordaban 
sus hazañas con el Emperador, en La Goleta o en el paso nocturno del Elba en Mühiberg, desnudos, a nado y con las espadas en la boca. Todo esto ya no volvería a repetirse. La Corte estaba en Madrid , el Imperio decaía y a aquellos orgullosos hidalgos solo les quedaba la oración y el recuerdo de su glorioso pasado, ante aquella España que se les venía abajo; que se arruinaba.. Y cuando ya aquellos chavales que éramos entonces, casi llorábamos de emoción; cambió de tono y dijo bruscamente: $\mathrm{Y}$ ahora ya podemos entrar a ver el Entierro del Conde de Orgaz.

En el cielo, había unas nubes que amenazaban tormenta, las recuerdo al cabo de tantos años, por que eran esas nubes del Greco, esas acartonadas nubes plomizas que hay en los fondos de sus cuadros. Nubes que la gente cree que son inventadas - paisaje onírico- lo llamaba Marañón $\mathrm{Y}$ yo os digo que no, que en Toledo hay esas nubes en verano, como también a fines de otoño hay un paisaje verde como el del Metropolitan Museum de Nueva York. No, Toledo es así de imprevisible y Domingo el Griego era mas realista de lo que se cree.

Se iniciaba ya la tormenta, bajamos a la barca, cruzamos el río y subiendo por el Pozo Amargo nos cayeron los primeros goterones.

Me dirás lector, que por que te cuento estos detalles que no te importan. Pero lo cierto es que aquella primera visión de Toledo impactó mi vida entonces infantil. Y ahora cuando voy a ver en "Entierro" los hombres que forman ese friso de cabezas, me parecen viejos amigos míos, a los que comprendo y que me cuentan sus ansiedades.

\section{Los años cuarenta: Marañón}

Pasaron muchos años, y no volví a Toledo. Conocí a Marañón en 1933 siendo yo todavía estudiante. Pero en aquellos años, quién era yo para ir invitado al Cigarral de "Los Dolores» como entonces se llamaba. Solía venir con mis amigos estudiantes a la entonces menos visitada que ahora ciudad. Nunca perdí el contacto con ella, pero este era solo un sedimento romántico en mis recuerdos de colegial.

Tras de la guerra civil, de casado ya; empecé a venir otra vez los Domingos a Toledo. Entonces todavía no se hacían fines de semana, se salía por la mañana de Madrid y por una deliciosa carreterita, intransitada, bordeada de acacias, se llegaba aquí. Venia poca gente, pero casi no había donde ir a almorzar. La Venta de Aires, que yo he llegado a conocer cuando era una pequeña y verdadera venta, con un arco romano detrás , estaba siempre llena, También existía el viejo Hotel Castilla. Pero mi mujer y yo, con mi hija niña, tomamos la costumbre de traer una me- 
rienda, subir donde actualmente está el Parador y hacer lo que ahora se llama un «picnic». Estabamos solos y veíamos Toledo a lo lejos Yo le explicaba a mi mujer desde allí, lo que yo sabía; y lo que no sabia lo inventaba. Para mi, todo era ya una leyenda. A la casa del Diamantista, que se llevó el río poco después en una crecida, la llamaba, no sé por qué «La Casa de la Cautiva». Todavía había barcas y podías alquilar una no solo para que te cruzase, si no hasta para dar un paseo y ver allá arriba las torres de Toledo. Frente a nosotros, cuando estabamos allí sentados en la Peña del Moro, había un jardín con una casa abandonada. Como aquello era, por San Lucas, la morería vieja, yo pensé que podía tratarse de la casa en ruinas de uno de aquellos moriscos que expulsó Felipe III y me dio por llamarla «El Jardín del Moro». Luego he reconstruido la historia de mi casa y es mucho mas moderna y vulgar, pero aquella fantasía se apoderó de mi y siempre desde entonces, así la he llamado.. Más tarde, como pasa con todo, la fui olvidando.

A todo esto, volvió Don Gregorio del exilio y el cigarral se abrió de nuevo. Algunos domingos me invitaba a almorzar y otros iba yo a verle por la tarde y me daba - siempre me acordaré- chocolate con migas-. Aquello estaba siempre lleno de invitados, la gente mas importante de Madrid y de fuera de España, y yo pintaba poco. De modo que así como muchos recuerdan a Marañón de su cigarral de Toledo, yo siempre he tenido mucho mas contacto con él en las mañanas del Hospital General.

\section{Compro una casa}

Al final de los años cincuenta, ya casi me había olvidado de Toledo. Era profesor de Madrid, dirigía una gran clínica y viajaba sin parar al extranjero. Me había «americanizado» un poco y creo yo que también había perdido, como se pierde tantas veces en la vida, la delicada sensibilidad de mis primeros años.

Más he aquí, que un día aparece $\mathrm{n}$ mi consulta, para que viese a su mujer, un farmacéutico muy conocido de Toledo. Y en esa conversación que siempre se liga con el marido, mientras que la paciente se prepara, saco a relucir aquella casa de Toledo. -Pero si está a la venta - me dice. Y no se llama como usted dice el «Jardín del Moro» si no el «Jardín de Ledesma». Supe así que era herencia de un conocido abogado de Toledo, que vivía como toda la gente pudiente de su tiempo en la «Calle de la Plata» o sus aledaños y que se había hecho aquel jardín para dar fiestas, que fueron famosas - como he sabido después 
por otros amigos- en los años treinta. Ledesma, había muerto sin hijos y sus herederos eran ocho o diez sobrinos, no querían vender el jardín. Fui a verlo, era una ruina. Los bombardeos del Alcázar le habían afectado mucho y la vieja casa estaba en el suelo. Malvivían allí tres familias a las que hubo que indemnizar para que se fuesen. Y una vez vacía la casa, al ir al notario, se vio que no estaba escriturada, cosa realmente rara en un jurista, pero así era. Gracias a los archivos parroquiales que tan divinamente se conservan en Toledo, pudimos averiguar al fin que era la antigua casa del párroco de la vecina Iglesia del San Lucas, así es que de Jardín del Moro no había nada, pero yo me había ilusionado tanto con esta leyenda y con este nombre que se lo dejé, y todavía así se llama y espero que se siga llamando.

La restauración de la casa fue una gran aventura que duró tres o cuatro años y que realmente todavía no ha terminado. No la voy a contar con detalle, pero si decir que en ella trabajaron todos los viejos artesanos de Toledo que vivían en un radio de doscientos metros. Así es que cuando se estrenó, fue un poco una fiesta del barrio, solo faltó como es costumbre en ellas, tirar unos cohetes. Traje muchas cosas de fuera. De Granada vino una fuente, de Sevilla cuatro columnas de mármol, de Plasencia un artesonado del XV y del mismo Toledo, de derribos, varios alfarjes, puertas de cuarterones y hasta los restos de una iglesia vieja con retablos churriguerescos. También compré bastantes cuadros y alguna que otra talla. Pero todo, o casi todo salió de aquí. Y reconstruí una vieja ermita arruinada, la «de la Candelaria» el barrio se llama desde tiempo inmemorial así "La Candelaria».

De entre las ruinas salieron dos sillares visigóticos que adornan la pared de mi comedor. Estas viejas piedras sueltas se encuentran por todas partes en la ciudad, pues las viejas iglesias de aquellos siglos, del VI al VII, sin duda se deshicieron varias veces, primero por moros y luego por cristianos.

Salió también un gran escudo de piedra con una cruz arzobispal, otra de Calatrava, una pluma y un sable. Es sin duda el escudo de un inquisidor. Este debió de ser el de párroco de San Lucas que tengo entendido que en tiempos de Fernando VII, fue el último inquisidor de Toledo. Así es que el Jardín de Moro es todo lo contrario de lo que yo me figuraba que era. Amarga reflexión para este aprendiz de historiador que soy yo mismo.

\section{En mi jardín}

Desde aquel año, en que estrené la casa, mi vida y mis costumbres cambiaron. Todos los fines de semana los paso aquí. Antes venía los 
Sábados, ahora los Viernes. Es decir que una tercera parte de mis días los paso en este «casco viejo» toledano. $\mathrm{Y}$ como soy un hombre tranquilo, que no da fiestas ni saraos, ni al que todo el mundo visita; pues cabe decir que mi vida aquí es un poco secreta. Pero dejadme cordialmente que os la cuente y que os diga como veo yo Toledo desde dentro. No por que interese a nadie lo que yo hago, si no simplemente para dar testimonio de como esta ciudad se ha ido adueñando un poco de mi.

Hay una Toledo de invierno y otra de verano. En la primera caen fuertes heladas. Un estanquillo que hay en un patio de mi casa, amanece con un dedo de hielo. En verano, se alcanzan los cuarenta grados, sobre todo en mi jardín que está como sabéis en la ladera sur. A fines de Agosto, cuando vuelvo de mi veraneo, mi casa me parece un viejo caserón manchego abandonado. Pero esta inclemencia de las estaciones, no me quita el entrañable amor con que siempre al volver, abro la puerta de mi casa. Aquí tengo mis libros y mis papeles. Aquí leo, escribo y medito. Y en contar mi vida de Toledo, tendría lector, que emplear mucho más tiempo del que me puedes conceder, así es que diré solo cuatro cosas.. La verdad es que no hay mucho que contar. Se dice que los pueblos felices no tienen historia. La verdad, es que los momentos de dulce felicidad tienen poco que recordar.

Yo, al revés que le pasaba a Don Gregorio, pierdo mucho el tiempo. No soy su «trapero" como él, si no su dilapidador. En Madrid tengo prisa, estoy mirando el reloj siempre, lo que a veces me hace parecer descortés con la gente. Aquí en Toledo, no. El tiempo fluye lento, y así pasan horas y horas. Si yo tuviera detrás de mi, una obra importante, bien científica o bien literaria, podría decir qué libros he escrito aquí en mi celda del piso bajo. Sin embargo, como lo que yo he hecho no vale gran cosa, a mi mismo se me olvida donde lo he escrito. Tampoco vale la pena hacer aquí un inventario. Como ya he dicho también que mi casa toledana no ha sido un brillante lugar de reunión, pues resulta que su historia se escribe en un pispás.

\section{Meditaciones toledanas}

Pero si como me habéis pedido, tengo que deciros cómo veo yo Toledo, del modo que recuerdo su pasado y procuro atisbar su futuro; era necesaria esta larga introducción para situar el problema: Para que os quepa una idea de quien os habla y desde donde lo hace. Y en fin os digo, que os habla quien se enamoró de esta ciudad de niño y que ya hombre, supo hacerse un rincón en ella, para descansar y para meditar. 
Ya conoces amigos, al hombre y a su morada. Esa «circunstancia» que como decía Ortega forma parte de nuestro yo. Ahora os pediría que tuvieseis la paciencia de escuchar de lo que este toleldano injertado piensa del «casco viejo» de esta ciudad y en general del de todas las ciudades milenarias.

Muy pocas ciudades antiguas del Mundo, tienen tan netos y tan intactos sus barrios medievales -Avila-, con sus grandiosas murallas, mas monumentales que estas de Toledo, desde luego conserva sus calles, sus iglesias y sus viejos palacios de un modo perfecto. Pero desde fuera, su paisaje en gran parte se ha perdido. Desde Sonsoles, desde el Valle Amblés, el Avila que se ve está desfigurada por casas nuevas hechas extramuros. Apenas desde los Cuatro Postes se ve todavía algo, pero rodeado de edificaciones modernas. Otro tanto sucede en Segovia, donde ha habido que parar la construcción de una casa que tapaba por completo el Acueducto. La vieja Valladolid ha desaparecido y Salamanca se conserva bella, pero difuminada.. En cambio Toledo ha crecido mucho en sus ensanches, pero desde cualquier parte que se la mire, conserva su «llustre Pesadumbre» igual que la vio Garcilaso, Los grabados antiguos presentan una imagen casi igual que la que vemos cuando en verano cenamos en la terraza de el Parador.

Vosotros toledanos, os alarmáis por que atraída por la facilidad de las viviendas, y por una vida mas cómoda - sólo aparcar el coche en la vieja Toledo es un problema insoluble- la gente joven se va a vivir al Polígono o a Santa Bárbara y la gente acomodada se hace chalets en las nuevas urbanizaciones. Y el casco viejo se despuebla. Tenéis en parte razón, por que una casa abandonada, se hunde. Una teja rota origina una gotera. El agua pudre las vigas y la techumbre al cabo de poco tiempo, se viene abajo. Si la vieja ciudad se queda vacía está condenada a morir. Es imposible restaurarla a expensas del Municipio, de la Comunidad o del Estado y al mismo tiempo, mantenerla vacía. Hay que sostener viva la ciudad y esa vida solo se la dan sus habitantes. ¿Como mantener llena Toledo? De este problema me quiero ocupar al final de estas líneas. Pero antes, recordemos lo que tenemos dentro de este conjunto, lo que a toda costa debemos conservar en su fragancia histórica, en su viejo aliento mozárabe. En su recuerdo de las tres culturas. Y en fin de ese corazón de España, que todavía sigue latiendo. Vamos a recordarlo juntos, tal y como yo lo veo y lo sueño.

\section{La Catedral, parroquias y conventos}

Os parecerá una blasfemia si digo que la Catedral, no es lo que da su carácter a Toledo. Tampoco el Alcázar. La verdadera ciudad, la 
que conoció Alfonso el Sabio, es esa masa de ladrillos y adobe que forma sus callejuelas medievales, sus cobertizos y sus plazuelas sin nombre. La Catedral es una bellísima masa de piedra, ajena a los ladrillos. Contaba Marañón, que un día le mostraba a Valle Inclán el paisaje desde la terraza del cigarral de Los Dolores. Y don Ramón soñando siempre con su pétreo Santiago le dijo con su ceceo tan poco gallego: «Ezte Toledo zi un día llueve mucho ze dezhace». No, no se ha deshecho, esta ciudad tiene una cochura de siglos, es la mas vieja cerámica de España.

Pero la Catedral - la Dives toletana - con una cantidad de bellezas acumuladas, como solamente quizá Roma alcance a tener, es la obra europeizante de un rey casado con una reina francesa y cuyo arzobispo era un monje de Cluní. Con la catedral, entra Europa en Toledo. Pero esta ciudad ya existía, es mas vieja, Recordemos que a través de su Escuela de Traductores, había contribuido a la creación de la Europa del Gótico. La cultura, no vino de norte a sur, si no al revés, subió de sur a norte.

En cambio en las parroquias y en algunos misteriosos conventos, se conserva, mas pura la esencia toledana. San Román, hoy convertida felizmente en museo; Santiago del Arrabal, maravilla mudéjar bien restaurada; San Andrés que es una joya; y tantas y tantas otras, sin olvidar a la iglesita siempre cerrada de Santa Eulalia, recuerdo pulcro de una iglesia mozárabe anterior a al conquista de Alfonso VI.

Los conventos: Santa Ysabel, los dos Santos Domingos, Santa Clara, San Clemente... joyas recónditas y que nadie visita. Por que el gran problema de estos monumentos, hoy ya únicos en el mundo, es que los ve muy poca gente. A Toledo hay que venir una semana entera o muchos domingos seguidos. Pero aun disponiendo de este tiempo, hay cosas que no se pueden ver: Las parroquias que solo abren a la hora de las misas, los Conventos que salvo Santo el Domingo el Antiguo, que felizmente se ha museificado, son de máxima clausura y esa Capilla de San José con sus dos Grecos fenomenales, que parece también un convento por que no hay manera de entrar en ella.

¿Como organizaríamos que todo este Toledo fuera visitable? Los conventos, podrían imitar a Santo Domingo o a la Encarnación y las Descalzas Reales de Madrid. Un convento de clausura es una delicia. No solo por las joyas de arte ocultas que contiene, si no por su ambiente y su silencio que nos transporta a otras regiones del espíritu. Entrar en un convento de estos, es un baño de paz. Yo he entrado pocas veces, lo hacía con frecuencia cuando me llamaban como médico. Vas por un claustro a ver a una monjita enferma, y otra te ve precediendo tocando una campanita. No encuentras a nadie, solo silencio y soledad. Estás 
fuera de este Mundo. No habéis visto amigos míos, la delicia que es en Madrid a un paso de la Gran Vía, estar en el claustro o ver el huertecillo de las Descalzas, con los rascacielos al fondo. En Toledo la impresión es todavía mucho mayor. Si las gentes de la ciudad, 'pudieran entrar en estas clausuras, claro es que limitadamente y a ciertas horas, lo de menos sería, con ser mucho, las antigüedades que se verían, lo verdaderamente importante sería el efecto psicológico; un verdadero baño de paz. Muchos melómanos van a un concierto para que el «alma se serene» como decía Fray Luis en su poema a Salinas. Pues bien, yo os digo amigos míos, que entrar en una clausura toledana es escuchar la mas pura de las melodías.

\section{Museos y Rincones}

En cambio en Toledo hay varios museos, nunca muy llenos, pero bien puestos y fáciles de visitar. En primer lugar el Museo de Santa Cruz, Allí en el centro mismo de la ciudad antigua, frente al Alcázar y al lado de Zocodover, está el antiguo Hospital de la Santa Cruz, fundado por el Cardenal Mendoza y que es ya de por si, una de las mas bellas joyas arquitectónicas de la ciudad. Sufrió mucho en el asedio dej Alcázar, pero en el cuarto centenario de la muerte de Carlos V, se restauró, se rehicieron sus maravillosos artesonados y se celebró una exposición sobre El Emperador. El Cardenal Plá y Deniel, lo convirtió en Museo Diocesano, trayendo a él todo lo que había en San Vicente y en muchas parroquias, que nadie sin su autoridad hubiera podido trasladar. Tiene una hermosa colección de Grecos entre ellos la famosa Asunción de Ovalle para mi una de las mas bellas obras del pintor. $\mathrm{Y}$ al fondo la bandera de Lepanto que se trajo desde la Catedral.

Otro museo, mas pequeño, pero muy notable, es el del arte visigótico, instalado en la restaurada iglesia de San Román. Esta es la mas antigua de las iglesias de Toledo, con restos visigóticos y mozárabes. Desde su torre, que domina la ciudad, es fama que Esteban Illán proclamó a Alfonso VIII aún niño. Se han reunido allí restos visigodos importante y hay una reproducción del tesoro de Guarrazar. No hay ningún edificio visigodo en Toledo, pero en cambio quedan muchas piedras sueltas, sin duda por que se destruyeron para hacer otros. En mi casa salieron entre las ruinas, dos sillares de esa época que ahora están franqueando el escudo del inquisidor en la pared de mi comedor.

Ya más pequeño, el Museo Sefardí, que en cambio es muy visitado por los turistas europeos y americanos, quizá por la rareza de un rastro tan importante de la cultura judía y por estar adosado a la 
Sinagoga del Tránsito y a la Casa y Museo del Greco. Esta que ya sabemos que no ha sido jamás la casa de Domínico Theotocopuli, fue fundada y creada sobre los restos de la casa de Samuel Halevy en la judería nueva. Yo he alcanzado a conocer a Don Benigno Vega Inclán su creador, siendo niño, pues era amigo de mi abuelo, El museo del Greco, con su vista de Toledo el Apostolado y el San Bernardino y sobre todo si se considera como parte de él a su vecino El Entierro. es realmente un museo de primer orden.

A un paso, está el Museo de Arte Moderno, de muy reciente creación. Lo más notable quizá sea la casa, pero su contenido es encantador. $\mathrm{Y}$ por fin la Catedral, que contiene un grandioso museo, con cuadros, joyas, reliquias y casullas. Pero por que hablar de museos en una ciudad, que es toda ella un museo, con dos sinagogas, dos mezquitas e infinitos rincones que me sería imposible describir. Solo puedo decir que un día paseando te encuentras en el, Callejón de los Niños Hermosos otro en el de la Muerte o en el ya visto por Becquer de Las Animas. El otro día no mas, ya empezadas a escribir estas líneas, me encontré en el de la Vida Pobre.

La más reciente creación no por ser de un artista moderno menos bella, es el Museo de Victorio Macho, que reconstruido por la Real Fundación Toledo, a la que desde aquí quiero saludar, ocupa un bellísimo lugar sobre el río.

\section{Puertas, puentes y murallas}

Cuando esto escribo se ha emprendido un gran proyecto, sostenido por la iniciativa privada, de restaurar las murallas de Toledo. Estas, no son como las de Avila, pero sobre que son mas antiguas -romanas y árabes - son de una belleza extraordinaria. Claro que para quedar bien necesitarán ser ajardinadas y sobre todo mantener su entorno limpio. Las puertas están siendo igualmente restauradas, la de Bisagra ya está casi terminada y la del Cambrón en plena obra va a quedar muy bien, La puerta de Alfonso VI como hoy día se la llama pero que es la puerta antigua de Bisagra de «bib-el.sahara» la que mira a la «Sagra» o llanura en árabe y las de Alcántara y Doce Cantos ya hace años que se restauraron.

Y los dos puentes, el de Alcántara que acaba se ser muy bien arreglado completo y el de San Martín que ya fue restaurado hace años, aunque la torre albarrana, quedó como estaba. 


\section{Lo que está mal: Limpieza, circulación iluminaciones, jardines}

El viejo Toledo, o sea la ciudad intramuros, es como he dicho portentosa, pero tiene grandes fallos. Claro es que está mejor que antes. Hace treinta años, en verano el Rodadero hedía, por que todas las basuras incluso el pescado podrido, se tiraban allí. Sin embargo, todavía es una ciudad sucia y el municipio tiene un presupuesto de limpiezas insuficiente. Sin embargo, en honor de los toledanos, tengo que hacer una observación, que tú lector podrás comprobar: Vas a un callejón perdido y no hay una basura. Los vecinos mantienen limpio su entorno como sucede también en los pueblos de Andalucía. Pero en cambio donde llegan forasteros, las botellas, los papeles y los vasos de plástico, se amontonan, sin contar los aledaños de las discotecas al día siguiente por la mañana. Esto quiere decir, que no son los toledanos los sucios, si no la totalidad de los españoles y sobre todo la masa dominguera y esto solo se podría arreglar educando y educando. Va para largo.

La circulación rodada es un desastre. Toledo está hecho para patearlo, sus callecitas no admiten los automóviles. ¿Pero quien se atreve a hacerlo entero peatonal como han hecho por ejemplo la ciudad antigua de Munich? Yo pronostico, que el alcalde que tal medida tomara, no volvía a salir elegido. Y sin embargo, algún día habrá que hacerlo, así no se puede seguir.

Las iluminaciones. Son bonitas, la ciudad de noche desde la Virgen del Valle o desde el Parador, está impresionante. El entorno de los puentes, perfecto. Pero la iluminación es escasa, cicatera. Ya sé que en España a diferencia de Francia, por ejemplo, la energía eléctrica es cara. Estamos pagando ahora la presión de los «verdes». El país vecino, a pesar de sus enormes ríos y los embalses que ellos generan, tiene 65 centrales nucleares nosotros solo unas pocas y las queremos cerrar. La carestía de la luz eléctrica se nota mucho en la noche de Toledo.

Pero sobre ser escasa, la iluminación es inconexa- Cada una va por su lado. No se ha estudiado una armonía de conjunto. La Catedral es blanca, con demasiada luz. La Academia enfrentada al Alcázar lo deslumbra. Y luego cada edificio se enciende por separado y a la hora que al encargado de dar a la llave se le ocurre. Los visitantes extranjeros se van a la cama antes de ver Toledo completo. Completo es un decir.

Lo bella que es la fuente en la rotonda del Arrabal con su jardincito, da idea de la cantidad de rincones ajardinados que se podrían hacer. Claro es que ello costaría caro. Más de sostener que de instalar. Se hizo un parque a orillas del río y se ha dejado perder, es una lástima.

Pero no quiero abrumar al ayuntamiento. Ya sé que hace lo que puede ¿Pero como hacer más? 


\section{El porvenir de Toledo}

Hace unos años, se hizo un estudio socioeconómico sobre el casco viejo. Lo tengo aquí a la mano. Los problemas están allí bien analizados y estudiados con gráficos y con tablas. Yo no añadiría nada. Pero quisiera como final buscar una solución a ellos. Claro es que a los que me lean este propósito, les ha de parecer ingenuo. Sin embargo voy a decir lo que pienso.

La vieja ciudad, es decir la Toledo intramuros, no es habitable en el sentido moderno de la palabra. La gente se va - ya lo hemos dichoa los barrios nuevos, y además hace bien. Es inútil confiar la conservación a sus moradores, por que para habitarla y hacerla habitable la desfiguran. Las instituciones públicas y las privadas - cajas, bancos, fundaciones - sería quimérico que sostuviesen una ciudad entera como si fuera un museo. A la vieja Toledo hay que vaciarla y darle al mismo tiempo una finalidad. Y esta es nada menos que ser la Capital Cultural de España. Se organizaban conciertos, ya no se dan apenas. Se pueden hacer representaciones teatrales, festivales de toda índole, congresos y convenciones. Mantener los centros universitarios dentro, no llevárselos fuera y atraer un turismo de mas calidad, mas culto. Estamos a una hora escasa de Madrid, frecuentemente tardo yo mas en salir de la ciudad, que luego en llegar a Toledo. Si cruzo la capital para ir a inaugurar una exposición o escuchar una conferencia, por poco mas puedo venir aquí. "La imaginación al poder», decían los parisinos hace treinta y un años. "La fantasía y la creatividad a Toledo», diría yo ahora.

Apenas hay un fin de semana, que no coja mi bastón y me pierda por Toledo. Digo literalmente perderme, por que es así, recorro lugares que nunca de visto, o que he visto ya y he olvidado, lo cual viene a ser igual. Y cuanto más recorro la ciudad, mas cuenta me doy de lo difícil que es conservarla. Que no perder el Casco Viejo es una tarea sobrehumana y que los toledanos y los españoles, no comprendemos la magnitud de este desafío. Pero precisamente por eso, por ser un desafío y no un simple problema, tenemos que recoger el guante $y$ luchar. No vale encogerse de hombros.

Pero me estoy dando cuenta ahora, que esta ciudad soñada, solo puede tener por base una España mucho mas culta que la de hoy. Hay que empezar por educar a las masas para poder reconstruir el casco viejo de Toledo. Sólo cuando lo españoles sepamos quienes somos y en frase de Américo, Castro, «cómo llegamos a serlo» Toledo, la vieja y querida eterna ciudad, podrá revivir de nuevo.

Toledo 1999 